\title{
FINITE ELEMENT ANALYSIS OF THERMOGRAPHY TECHNIQUE FOR DEFECT IDENTIFICATION IN CONCRETE SLAB
}

\author{
R. Ravichandran ${ }^{1}$, K. Sivasubramanian ${ }^{2}$, K.N. Lakshmikandhan ${ }^{3}$, P. Sivakumar ${ }^{4}$ \\ ${ }^{1}$ Scientist, CSIR-Strcutural Engineering Research Centre, Chennai-600113, India \\ ${ }^{2}$ Scientist, CSIR-Strcutural Engineering Research Centre, Chennai-600113, India \\ ${ }^{3}$ Scientist, CSIR-Strcutural Engineering Research Centre, Chennai-600113, India \\ ${ }^{4}$ Scientist, CSIR-Strcutural Engineering Research Centre, Chennai-600113, India
}

\begin{abstract}
Non-destructive evaluation is an area of focussed research around the world. Through non-destructive evaluation it is aimed at evaluating the integrity of concrete and identify the location of defects like voids and honeycombs. While most of these methods rely on wave propagation, the infrared thermography technique uses heat conduction principles to identify defects at shallow depth. The infrared thermography technique is a non-contact non-destructive testing technique which makes it possible to evaluate the test medium independent of its surface characteristics. Also, the ability of the infrared thermography camera to capture and assess a surface area at every time instant makes it an interesting technique to pursue research on.

In the present work, it is proposed to examine the possibility of defect identification using the infrared thermography technique by employing the finite element analysis. For this study, two case studies have been carried out. For the analysis a standard commercial FEM package has been used and the heat transfer analysis is carried out using ten node tetrahedron elements by incorporating the thermal properties. Heat is applied from one surface and the evaluation is carried out from the same surface. Encouraging results have been obtained on the application of the thermography method. In the present study, it has been observed that the thermography method could be effectively applied for large defect identification up to a depth of 90mm from the investigating surface.
\end{abstract}

Keywords: thermography, finite element analysis, concrete, defect identification, heat conduction

\section{INTRODUCTION}

In this study, an approach based on $3 \mathrm{D}$ heat transfer is employed to simulate the heat flow interaction with the defects in the concrete slabs. The model intends to contribute to the interpretation of results from infrared thermography data and to explore the features of this nondestructive testing technique when it is used to detect and characterize defects. Infrared thermography is a technique that may be used for evaluating surface temperatures of objects, based on the fact that all bodies with temperature above the absolute zero $(-273.15 \stackrel{\mathrm{C}}{\text { or }} 0 \mathrm{~K})$ continuously emit thermal energy within the infrared wavelength band, which lies on the electromagnetic spectrum between visible light and microwaves. When captured by thermography cameras this emission is converted into an electric signal, allowing the generation of images that represent the distribution of temperatures on the surface of the targeted body. Infra-red thermography has found applications in swine flu detection; cancer diagnosis ${ }^{1}$; heating of circuit boards, transformers and equipment reliability ${ }^{1,2}$; and monitoring molten slag in iron and steel factories ${ }^{3,4}$. Here, the thermography method applied is the passive type. In passive type IRT the thermography method rely on the ability of the diagnosing object to emit infra-red rays based on the inherent heat in the test medium. In all these cases, passive thermography could be sufficient. However, the evaluation of composites in aerospace industry ${ }^{5-7}$ uses active infra-red thermography. In the active type IRT, filtered incandescent source or infrared diode illuminator or filtered xenon flash is used to pulse heat energy into the object for a short period of time. The thinner composite sections have been found to respond to the thermal pulse and thus yield differential thermal gradients if defects are present.

The fact that concrete does not possess inherent heat constrains the applicability of IRT to concrete and masonry structures. This implies that external heating source needs to be employed. The massive size of the structural elements in civil engineering demand much stronger heating. Hence, the heating lamp being used as source in aerospace engineering could not be used for concrete because of their lower heat intensity.

Research on the role of infra-red thermography for civil engineering applications is being currently pursued ${ }^{8}$. Thus, extensive research, in the recent past, have led to the detection of defects in pavements ${ }^{9}$, embankment deterioration $^{10}$ and non-destructive testing in concrete ${ }^{11,12}$. However, in India, limited research or application of this method has been observed.

In the present work, finite element simulation has been carried out to identify defects in a concrete slab. The defects have been placed at different depths. Through this study, it 
is aimed at improving the understanding on the defect identification in concrete slabs by effectively using the thermograms obtained after the heat transfer investigation.

\section{INFRARED THERMOGRAPHY}

IR thermography relies on infra-red rays emitted by the test object to develop the thermograms. Sir William Herschel discovered the presence of infra-red rays in visible light in 1800. Only in 1830, the first detectors were developed for infra-red rays. Infra-red thermography is based on the principle that all bodies, above absolute zero temperature $(0$ $\mathrm{K}$ ), emit heat / thermal infrared radiations. It has also been observed that the intensity of this radiation depends on the wavelength and the body's temperature ${ }^{13}$. Subsequently the focus of research shifted towards the developments on IR detectors till the mid-1900s. With the development of better IR detectors, the thermography technique became popular to be used in various applications. Here, the Planck's law is used to evaluate the radiance of heat from a black body while its inverse is used to evaluate the temperature on a black body. Later, the Wien's law and Stefan-Boltzmann law have strengthened the thermography method in evaluating the temperature on the body surface ${ }^{13}$.

The thermography method uses a camera capable of detecting the radiations/rays in the infra-red zone. The camera and the equipment are shown in Fig. 1. The camera resembles a camcorder but detects variations in infra-red emission and displays them as thermal gradients. This feature of the camera is being used in thermography method. It needs to be mentioned here that the IRT method is a noncontact method making it possible to conduct the evaluation process at a distance from the test object. Also, the IRT method does not involve the use of any radiations harmful to the operator but on the contrary only uses the radiations from the test object for the evaluation. Hence, this technique is harmless and encouraging to use.

\section{FINITE ELEMENT ANALYSIS}

The finite element analysis of the thermal analysis problem has been carried out using a standard commercial finite element package. Heat transfer analysis can be conducted on a concrete slab by either or a combination of the two methods, namely, uncoupled and coupled heat transfer analysis. In the present study, the identification of defects in concrete using heat conduction involves only the uncoupled heat transfer analysis. In this study, the temperature field is calculated ignoring the details of the stress/deformation state in the bodies being studied.

It needs to be noted that the heat transfer problems involving conduction, forced convection, and boundary radiation can be analysed by using a standard commercial Finite Element Analysis package. These pure heat transfer problems can be transient or steady-state and linear or nonlinear with inclusion of conduction, boundary convection, and boundary radiation. The principles of the steady state technique are based on creating a steady temperature gradient across a known thickness of a specimen by controlling the heat flow from one side to another. This method requires a longer time to establish the steady state temperature gradient across the specimen where the gradient is required to be large. This method of analysis is applicable only to the specimens which are larger.

In general, a steady state heat conduction problem consists of finding the temperature at any point within a specified solid whose surface has been subjected to a known set of boundary conditions. Fourier's law and Laplace's equation are utilized to assemble the temperature field equations under appropriate boundary conditions in the 2D Cartesian coordinates, while the finite element method is employed to calculate the temperature field and model the heat transfer. On the other hand, transient analysis techniques perform a measurement during the process of heating. The advantage is that these may be made relatively quickly. The disadvantage is that the mathematical analysis of the data is in general more difficult than the steady state methods.

In the present work, a three-dimensional finite element analysis is formulated and implemented to predict both steady state and transient heat transfer in concrete slab specimens with embedded defects. The model provides surface temperature contours which are the prime interest of infrared thermography. Two different specimens with identical thermal properties are considered for this study, one with defects at different depths and the other with varying sizes.

\section{RESULTS AND DISCUSSIONS}

In the present work, ten node tetrahedron elements have been employed for meshing of the finite element model. The finite element model has been created to replicate, in all aspects, the phenomenon that occurs in an experimental study. Two slab specimens are considered for the analysis in the present work.

The first slab is a specimen (Slab-1) with six defects. The slab is of size $1500 \times 1000 \times 150 \mathrm{~mm}$. The defects are of uniform size $150 \times 150 \times 25 \mathrm{~mm}$ and are placed at depths of $15 \mathrm{~mm}, 30 \mathrm{~mm}, 45 \mathrm{~mm}, 60 \mathrm{~mm}, 75 \mathrm{~mm}$ and $90 \mathrm{~mm}$ from the top surface. The finite element model created for this investigation is shown in Fig. 2. This specimen is considered with the aim of understating effect of heat flux on the defect identification process. Also, it is aimed at arriving at the magnitude of heat flux required to investigate a specimen with defects at $80 \mathrm{~mm}$ depth.

The Concrete slab is modelled with three-dimensional quadratic tetrahedron elements. The analysis uses the material and thermal properties including density as 2400 $\mathrm{kg} / \mathrm{m}^{3}$, conductivity as $1.8 \mathrm{~W} / \mathrm{m} .{ }^{\circ} \mathrm{C}$ and specific heat as $0.18 \mathrm{kcal} / \mathrm{kg}^{\circ} \mathrm{C}$.Fig. 3 shows the meshed model used for the analysis of the Slab-1. Before carrying out the heat transfer analysis, it is first ensured that the specimen attains room temperature of $303 \mathrm{~K}$, as is observable in the reality. To carry out the analysis, the steady state analysis is considered with the boundary condition involving the bottom four corners maintained at a temperature of $303 \mathrm{~K}$. In the present 
work, it is proposed to employ the top surface of the specimen as the heating surface and the monitoring surface. Towards this, the heat flux is applied on the top surface. The heat flux is gradually applied to avoid unwanted effects. Fig. 4 shows the boundary conditions and the heat loading applied on the specimen Slab-1.

In the next step, the Transient Analysis is invoked with the surface load of $0.8 \mathrm{~W} / \mathrm{m}^{\wedge} 3 \mathrm{~K}$ and the analysis is performed and the thermogram is plotted for the variation of temperature on the surface. The thermogram of the slab obtained using FEA is shown in Fig. 5. The thermogram reveals thermal gradient variations at the locations of the defects. From the thermogram, it is observed that all the defects could be identified. The thermogram in Fig. 5 indicates the defect locations using a different color. From the study it has been observed that with a heat flux used in this study, it is possible to investigate the presence of defects upto a depth of $90 \mathrm{~mm}$, provided defects are as large as $150 \times 150 \mathrm{~mm}$.

The next specimen (Slab-2) is a slab with the same size as Slab-1. The slab has six defects of varying sizes. The size of defects are $25 \times 25 \times 25, \quad 50 \times 50 \times 25, \quad 75 \times 75 \times 25$, $100 \times 100 \times 25,125 \times 125 \times 25,150 \times 150 \times 25 \mathrm{~mm}$ and are placed at uniform depth of $80 \mathrm{~mm}$ from the top surface. The finite element model of Slab-2 is shown in Fig. 6.

The Slab-2 has got identical properties as the Slab-1. Hence, the material and thermal properties, element type, boundary condition, loading and the analysis steps are kept identical to the previous analysis. After performing the analysis the thermogram of the Slab-2 is obtained and is plotted in Fig. 7. From the thermogram, it can be observed that the heat flux is sufficient to aid in the identification of defects larger than $75 \mathrm{~mm}$. With this heat flux, the identification of the defects of larger size is relatively easier when compared to the smaller ones.

Thus, it can be concluded that IR thermography can be used for shallow depth defect identification in concrete structures.

\section{CONCLUSION}

This present work attempted to simulate the infrared thermography for non-destructive evaluation of concrete slabs. For this, a standard finite element package has been employed for modelling and analysing the specimens by simulating heat transfer into the specimens. Towards this concrete specimens with defects placed at different depths and those of varying sizes placed at constant depths have been investigated. From the first part of the study, it has been observed that the defects could be identified up to a depth of $90 \mathrm{~mm}$ using the IR thermography technique. Next, the analysis of the second specimen was carried out. From the study, it has been observed that the defects of size larger than $75 \mathrm{~mm}$ could be identified, when the same heat flux used for analysing Slab-1 is used. The results are encouraging and inspire to carry out experimental investigations on the slabs based on the understanding obtained from these investigations.

\section{ACKNOWLEDGEMENTS}

The paper is being published with the approval of the Director, CSIR-SERC.

\section{NOTATIONS}

FE - Finite Element

FEM - Finite Element Method

IR - Infrared

IRT - Infrared Thermography

NDT - Non-Destructive Testing

\section{REFERENCES}

[1] Vreugdenburg, T.D., Willis, C.D., Mundy, L, Hiller, J.E., "A systematic review of elastography, electrical impedance scanning, and digital infrared thermography for breast cancer screening and diagnosis", Breast Cancer Research and Treatment, V. 137, No. 3, 2013, pp. 665-676.

[2] Jadin, M.S., Taib, S., "Recent progress in diagnosing the reliability of electrical equipment by using infrared thermography", Infrared Physics \& Technology, V. 55, No. 4, July 2012, pp. 236-245.

[3] Usamentiaga, R., Garcia, D.F., Molleda, J., Bulnes, F.G., Orgeira, V.G., "Temperature tracking system for sinter material in a rotatory cooler based on infrared thermography", Proc. of Industry Applications Society Annual Meeting, 2013 IEEE, Lake Buena Vista, FL, 611Oct. 2013, pp 1-8.

[4] Zhang, Z, Bin, L, Jiang, Y, "Slag detection system based on infrared temperature measurement", Optik International Journal for Light and Electron Optics, V. 125, No. 3, Feb. 2014, pp. 1412-1416.

[5] Manohar, A, Scalea, F.L., "Defect Detection in Composite Structures Using Lock-In Infrared Thermography, Residual Stress", Thermomechanics\& Infrared Imaging, Hybrid Techniques and Inverse Problems, V. 8, Conference Proceedings of the Society for Experimental Mechanics Series, 2014, pp 135-141.

[6] Yang, B, Huang, Y, Cheng, L, "Defect detection and evaluation of ultrasonic infrared thermography for aerospace CFRP composites", Infrared Physics \& Technology, V. 60, September 2013, pp. 166-173.

[7] Carosena, M, Cinzia, T, "NonDestructive Evaluation of Carbon Fiber Reinforced Polymers with Ultrasonics and Infrared Thermography: An Overview on Historical Steps and Patents", Recent Patents on Materials Science, V. 5, No. 1, pp. 48-67(20).

[8] Milovanovic, B, Pecur, I.B., "The Role of Infrared Thermography in Nondestrcutive testing of Civil Engineering Structures", Matest 2011 Proceedings/Krnic, Niksa (ed) - Zagreb, 2011.

[9] Dumoulin, J, Ibos, L, Marchettiand, M, Mazioud, A, "Detection of non-emergent defects in asphalt pavement samples by long pulse and pulse phase infrared thermography", European Journal of Environmental and Civil Engineering, V. 15, No. 4, 2011, pp. 557-574. 
[10] Chiang, C.H., Cheng, C.C., Hsu, K.T., "Inspection of Deteriorated Coastal Embankments Using Radar, Thermography, and Impact-Echo", Nondestructive Testing of Materials and Structures, RILEM Bookseries V. 6, 2013, pp. 927-933.

[11] Belattar, S, Rhazi, J, Ballouti, A.E., "Non-destructive testing by infrared thermography of the void and honeycomb type defect in the concrete", International Journal of Microstructure and Materials Properties, V.

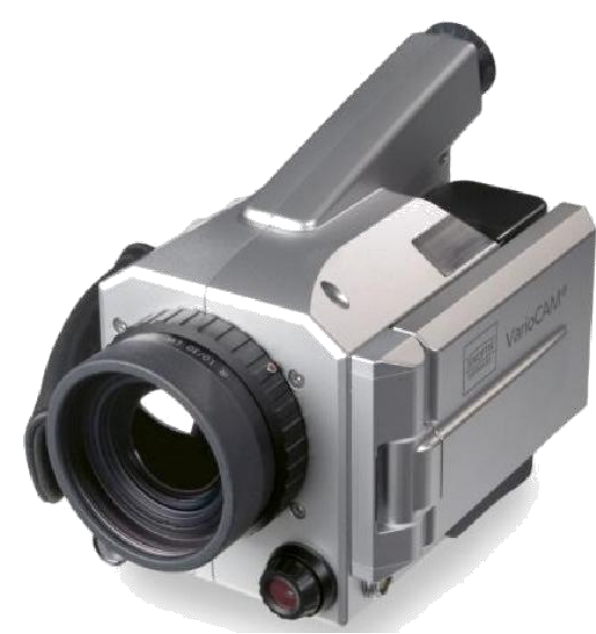

(a) IR Camera
7, No. 2-3, 2012, pp. 235-253.

[12] Carcangiu, S, Cannas, B, Concu, G, Trulli, N, "Modeling of Active Infrared Thermography for Defect Detection in Concrete Structures", Proc. of 2012 COMSOL Conference, Milan, 2012.

[13] Minkina, W, Dudzik, S, "Infrared Thermography: Errors and Uncertainties”, John Wiley \& Sons, 2009, 212 pages.

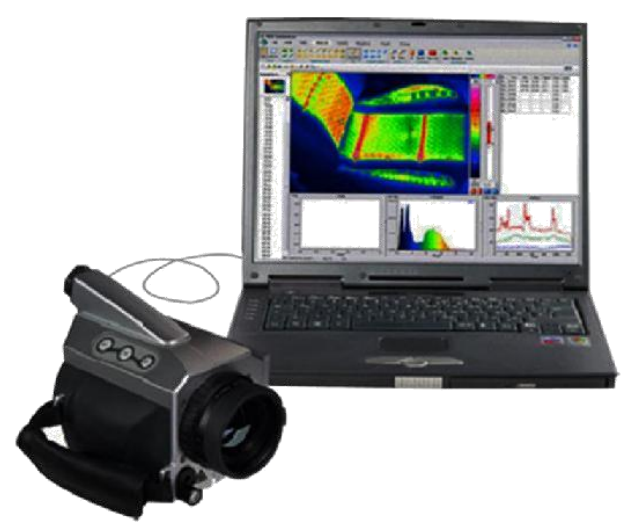

(b) Camera and processing laptop

Fig 1 Infrared thermography equipment

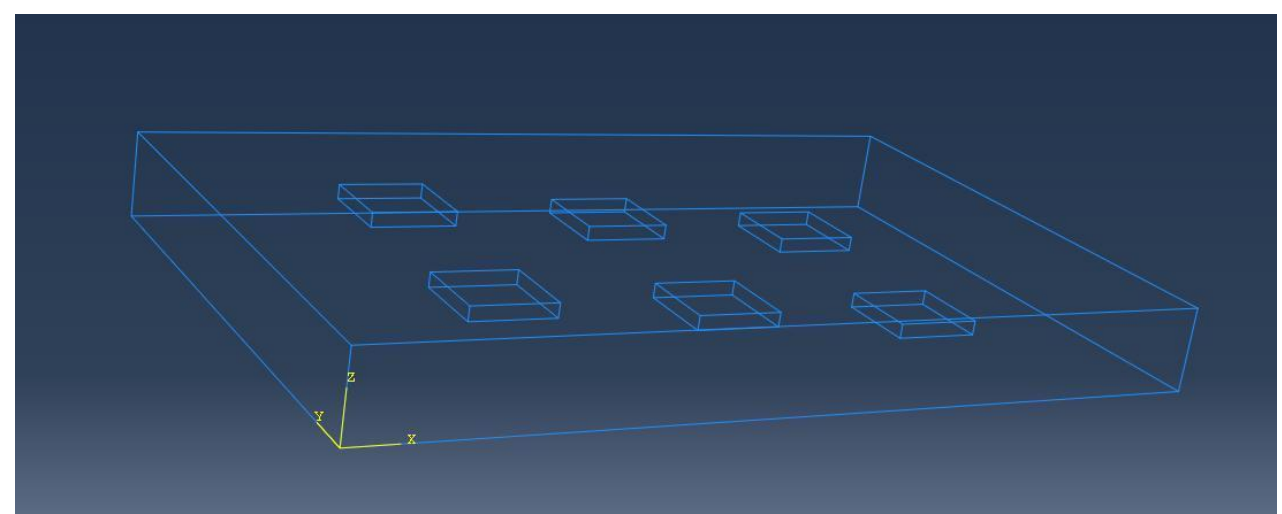

Fig 2 Finite element model of the test specimen

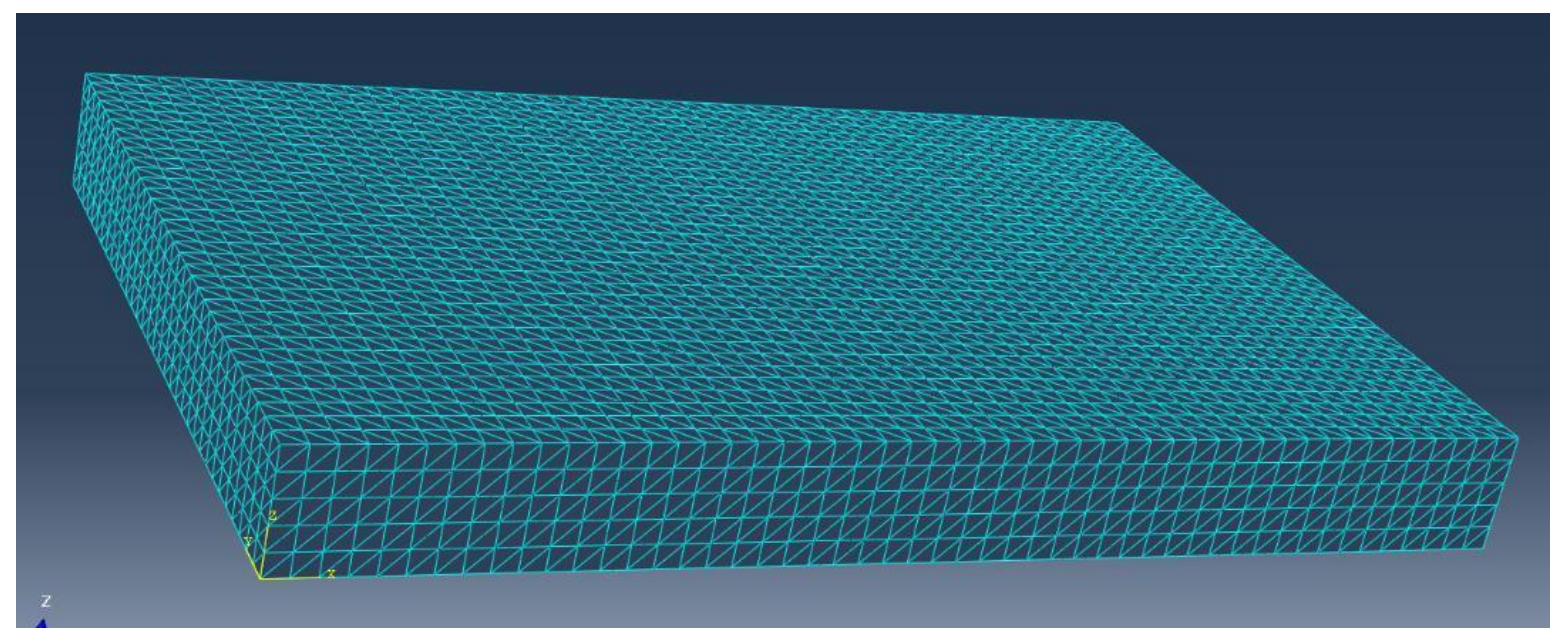

Fig 3 Meshed model of Slab-1 


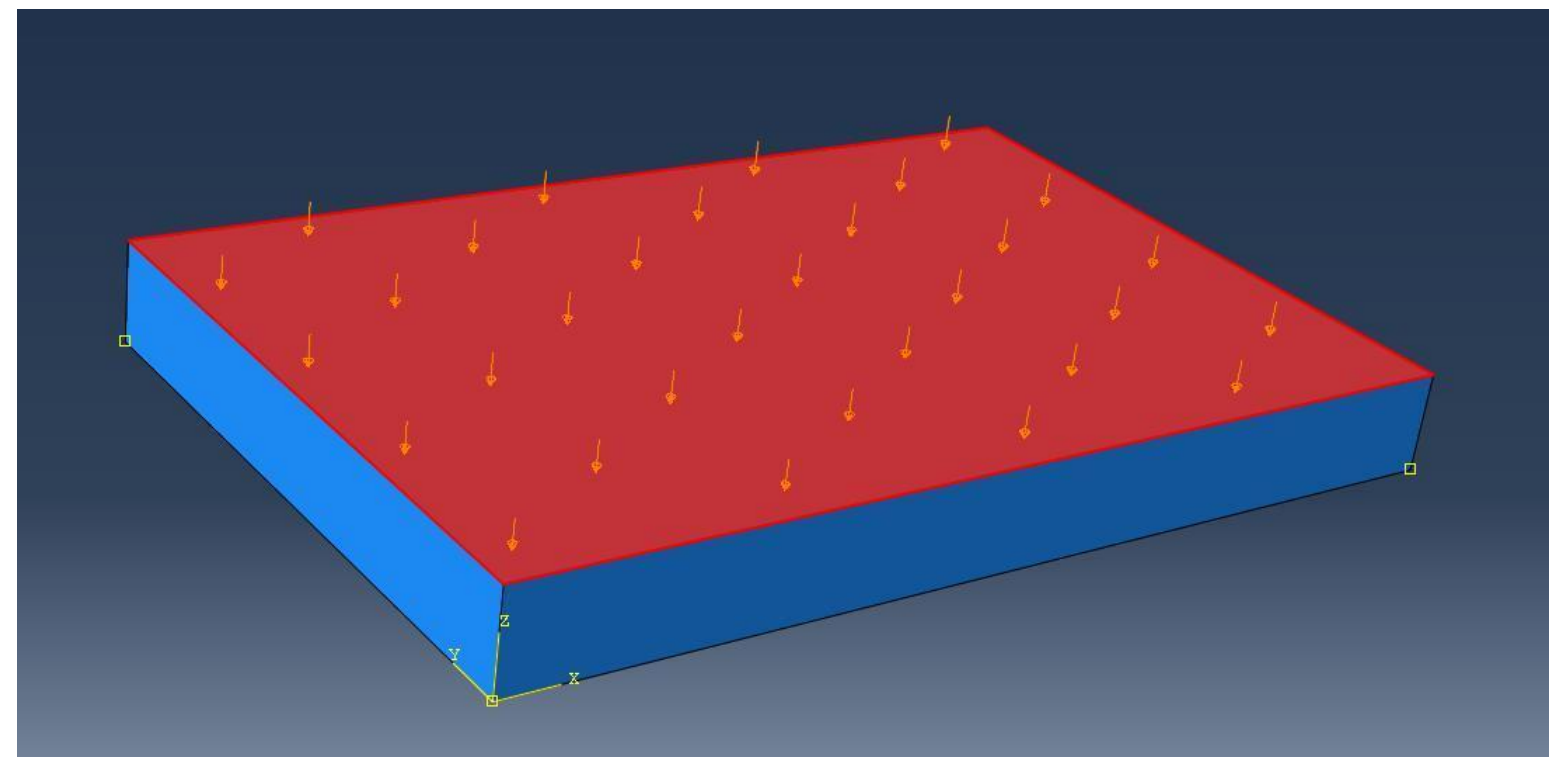

Fig 4 Finite element model of the specimen Slab-1

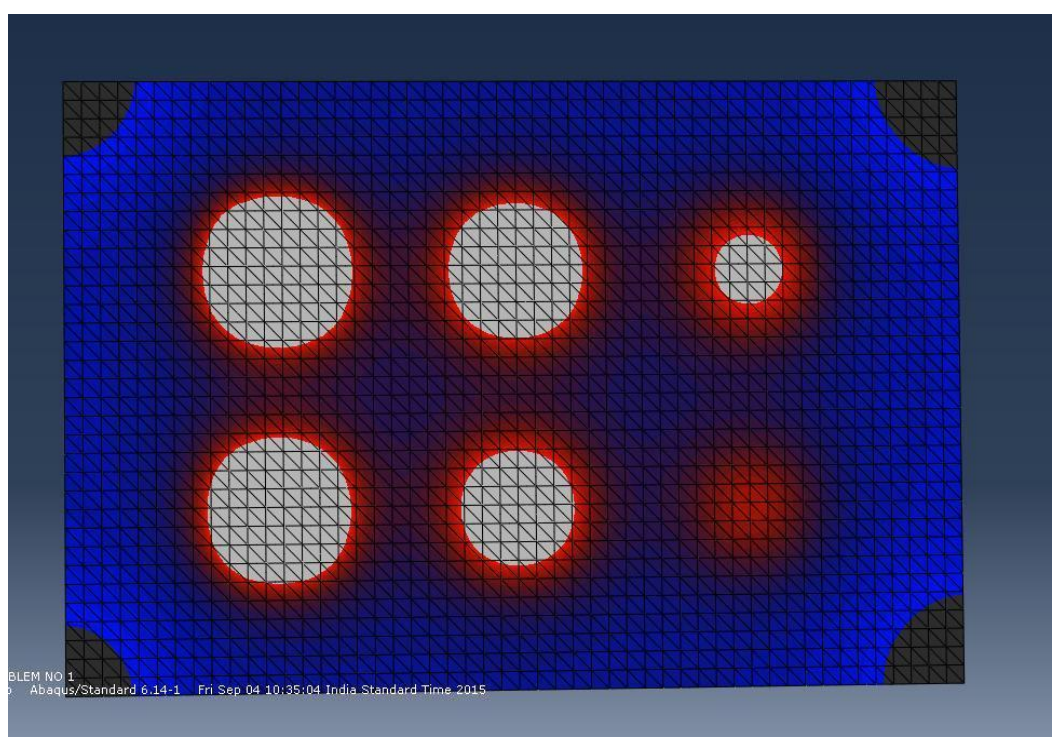

Fig 5 Thermogram of Slab-1 obtained using FEA

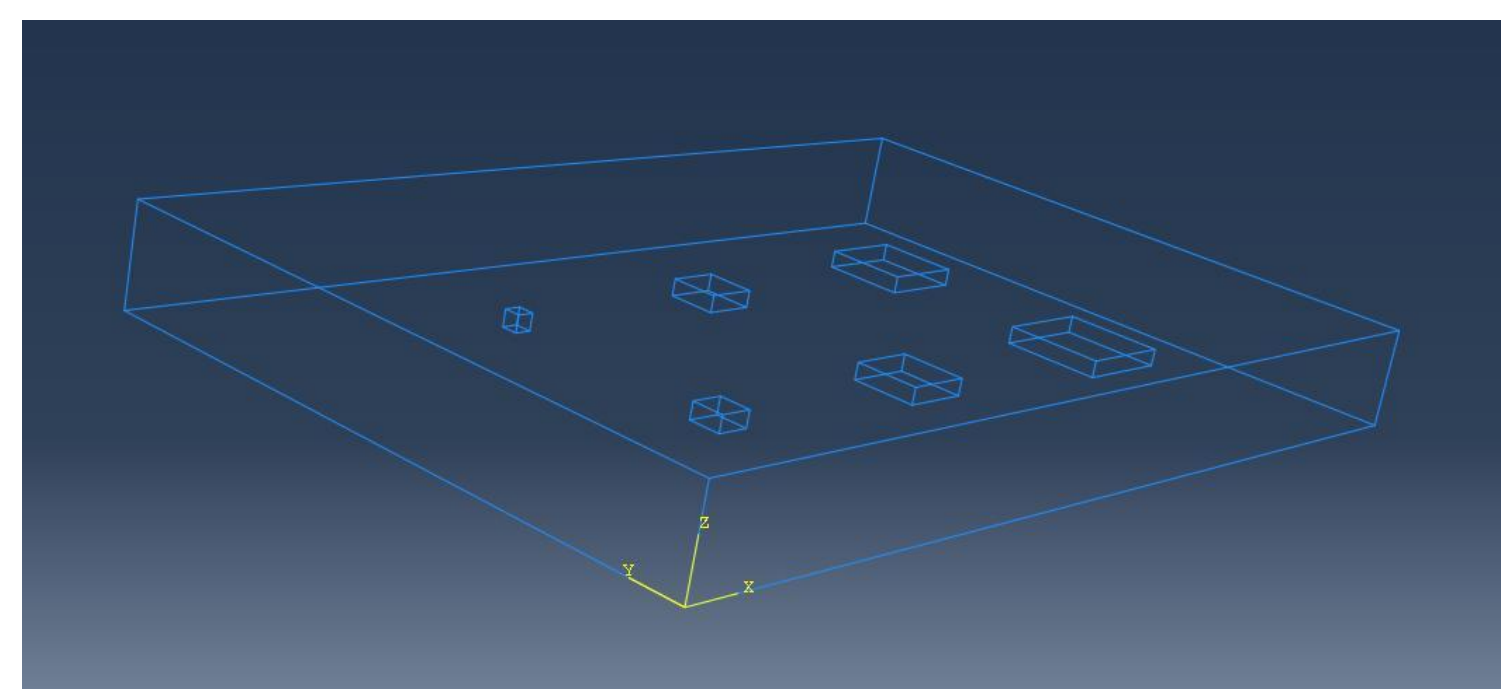

Fig 6 Finite element model of the specimen Slab-2 


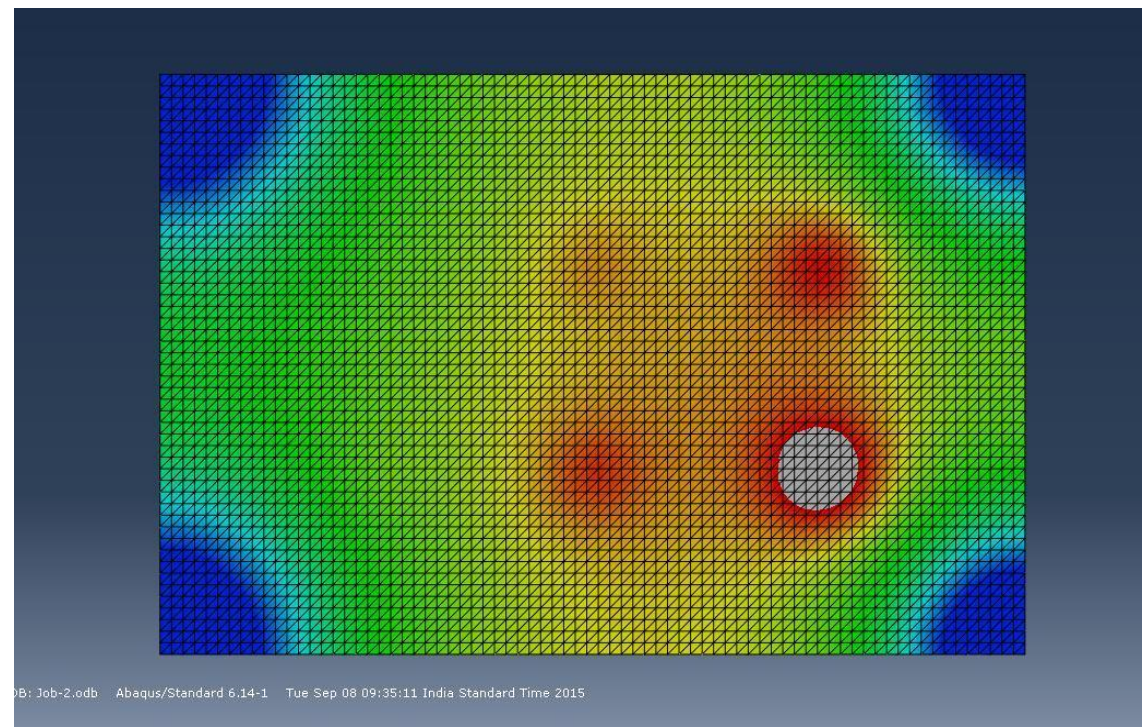

Fig 7 Finite element model of the test specimen 